\title{
A PRODUÇÃO DE ESPAÇOS, MEMÓRIAS E HISTÓRIAS SOBRE A CIDADE DE ARAGUARI-MG
}

Maria Gisele Peres

RESUMO: Este artigo tem como objetivo apresentar algumas reflexões sobre a construção de marcos de memória que ganharam espaço no circuito de difusão de uma história que foi dada a ler sobre a cidade de Araguari-MG. Nele sigo a trilha de evidências que permitem compreender a construção de sentidos sobre seu passado. Narrativas de viajantes, livros de memorialistas códigos de postura que objetivavam organizar os espaços da cidade, abrem a oportunidade de refletir sobre o processo de produção social de lembranças e esquecimentos, descortinando também diferentes tentativas de intervenção nos espaços que a constituem.

PALAVRAS-CHAVE: Memórias. Espaços. Cidade.

ABSTRACT: This article goal is to present some reflections about memory milestone creation. These milestones have been motive of some attention as they diffuse a story on the history of Araguari, state of Minas Gerais, Brazil. In this paper, I follow a trail of evidences that allow us to understand the construction of the past. Travel narratives, memoirs, and social conduction books, which had the intent of organizing the city spaces, open the opportunity of reflection about social production process of creating memory and oblivion. This reflection discloses many attempts of intervention in the constitutive spaces of the city.

KEYWORDS: Memories. Spaces. City.

Ao pesquisar o processo no qual foram produzidas, selecionadas e publicizadas memórias sobre a cidade de Araguari-MG foi possível desvendar a construção de uma versão sobre a história dessa cidade, a qual deixou de fora outras histórias, especialmente as relacionadas aos viveres de trabalhadores. ${ }^{70} \mathrm{~A}$ tese de doutorado, defendida no Programa de Pós-Graduação em História da Universidade Federal de Uberlândia, teve como objetivo principal desconstruir consensos, problematizando marcos de memórias instituídos, para que fosse possível encontrar, então, outros sentidos sobre o viver nessa cidade. Neste artigo, apresento algumas reflexões que compõem a tese de doutorado que desenvolvi. Para isso, focalizo especialmente a construção de marcos que ganharam espaço no circuito de difusão de uma história que foi dada a ler sobre a cidade; processo que, ao ser investigado, descortinou também diferentes tentativas de intervenção nos espaços que a constituem.

Nessa direção, com a intenção de apresentar uma cidade que vai sendo delineada nas disputas $^{71}$, tomo como ponto de partida a década de 1980 , momento no qual teve início um "inventário" de dados e fatos sobre Araguari que, posteriormente, deram vida a seu Arquivo Público Municipal.

\footnotetext{
* Professora de História do Instituto Federal Catarinense, campus São Bento do Sul. Doutora em História Social pela Universidade Federal de Uberlândia.

70 As reflexões presentes neste artigo compõem a tese de doutorado: "Espaços e Linguagens: marcos de memórias nas histórias de Araguari-MG/1888, orientada pela Prof. ${ }^{\text {D }}$ Dr. ${ }^{\text {a }}$ Célia Rocha Calvo, no Programa de Pós-Graduação em História da Universidade Federal de Uberlândia, defendida em 14 de agosto de 2014.

71 Sobre essas reflexões, foi fundamental a leitura do texto: FENELON, Déa Ribeiro. Introdução. (FENELON, 1999 , p. 5-13).
} 
Ao problematizar as disputas que se colocavam pela cidade naquele tempo presente (1988 - ano da comemoração do seu centenário), foi possível entender como aquelas escolhas contribuíram para a produção social do esquecimento por meio do silenciamento e/ou pela apropriação e expropriação dos sentidos que referenciavam outros modos de viver.

Essa percepção foi aguçada quando entrei em contato com o livro produzido em comemoração aos 100 anos da cidade. "Araguari: cem anos de dados e fatos" é a reunião e talvez um resumo de vários documentos considerados oficiais - especialmente decretos, atas e fotografias - que narram a história de sua "evolução": de arraial até o momento no qual foi publicado. De caráter informativo, a história que por meio dele ganha visibilidade anula as tensões vividas.

A leitura a contrapelo - lançando novas questões aos mesmos suportes de memórias que foram utilizados como meios de fundamentar os marcos explicativos sobre o passado de Araguari que estavam sendo produzidos e/ou reforçados na década de 1980 - possibilitou novos olhares sobre ela, abrindo a oportunidade de acompanhar diferentes dimensões da vida na cidade e a recorrente busca por projetar a imagem de uma cidade "desenvolvida". A partir daí foi possível problematizar também escolhas que contribuíram para produzir social e espacialmente diferenciações na cidade.

Foi nesse sentido que o processo de amadurecimento das reflexões conduziu à percepção de que o fundamental não é apenas apontar que existe uma história sobre a cidade que se tornou "oficial", mas, sim, buscar apreender os diversos sentidos e interesses que fazem da memória um campo de disputas: as tensões, os conflitos, as resistências, as aceitações e as conformações que compõem o viver nesta cidade e que conduziram à produção de tal história.

Por isso, a categoria memória não pôde ser vista como um simples campo de preservação, mas fundamentalmente como um campo de lutas. Isso porque o embate entre os diferentes interesses produzidos socialmente nas relações que são classistas não pode ser desvinculado da produção de memórias que se tornaram públicas e, consequentemente, dos sentidos que são atribuídos ao passado.

Ao falar sobre memórias públicas refiro-me àquelas memórias que ganharam projeção no espaço público por meio das escolas, dos poderes públicos, da imprensa, de livros, de celebrações, nos nomes de ruas e praças, assim como por meio de monumentos. Dialogando com as proposições colocadas pelo Grupo de Memória Popular, considero que refletir sobre essas memórias possibilita refletir também sobre o processo de produção social da memória, uma produção que, segundo o Grupo, é coletiva, na qual "todos participam, embora, de maneira desigual" (GRUPO MEMÓRIA POPULAR, 2004, p. 283).

Nessa direção, se fez importante compreender o processo dessa produção, questionando como e por que ocorreu a cristalização de algumas versões sobre o passado da cidade, buscando problematizar especialmente o lugar reservado às memórias dos trabalhadores em Araguari: como elas foram incorporadas ou silenciadas ao longo de um processo de institucionalização de uma história sobre a cidade?

Assim, foi a partir dessa percepção que se impôs, de forma mais contundente, a necessidade de compreender sua natureza histórica. Afinal, quais são os sentidos de sua existência? Na busca por essa compreensão, deparei-me com seus espaços saturados de memórias. O traçado que ganhava forma e sentido nos suportes pesquisados indicava diferentes tentativas de ordenar e delimitar seus espaços com a intenção implícita - outras vezes explícita - de estabelecer o lugar social que caberia às classes que a compõem.

Se a paisagem da cidade, como propõe Marcel Roncayolo, não é natural, mas uma construção histórica, ${ }^{72}$ quais as razões para seu traçado? Como ele se conecta ou não aos marcos de poder que foram instituídos?

Ao buscar compreender sua natureza histórica, a construção de marcos de poder e a historicidade dos modos de viver que nela se fizeram, especialmente de trabalhadores,

\footnotetext{
${ }^{72}$ Refiro-me aqui ao texto: Roncayolo (1984, p. 396-487).
} 
encontrei no livro "Do Rio de Janeiro a Goiás - 1896 (A viagem era assim)" caminhos para a reflexão proposta.

Este livro foi organizado e publicado em 1961, por Maria Paula Fleury de Godoy, a partir do diário escrito por sua mãe, Augusta de Faro Fleury Curado, escrito em 1896, e que tinha como intenção registrar a viagem que esta empreendeu com sua família, como o próprio título indica, da então capital federal até a antiga capital do estado de Goiás. A organizadora participou também da viagem, na época ainda criança, e fundamenta sua decisão em publicar as memórias de sua mãe como uma forma de homenageá-la.

Augusta de Faro Fleury Curado, filha do conselheiro André Augusto de Pádua Fleury, nasceu em Curitiba, quando sua família lá residiu no período em que seu pai foi Governador do Paraná; todavia, viveu parte de sua juventude na cidade do Rio de Janeiro. Conheceu Paris quando seu pai representou o Brasil em um Congresso de Direito Penitenciário em Estocolmo. Também conheceu o Espírito Santo e o Ceará, acompanhando sua família quando o conselheiro atuou como governador desses estados. Além disso, viveu em São Paulo no período em que ele dirigiu a Faculdade de Direito. O marido, Sebastião Fleury Curado, seu primo, foi advogado e político. Embora o tenha conhecido em São Paulo, este, nascido em Goiás, decidiu mudar-se do Rio de Janeiro para sua terra natal. Daí o motivo da viagem.

No prefácio, escrito em 1961 pela filha, chama a atenção a descrição da chácara onde viveram na Cidade de Goiás, os costumes de sua família e o temperamento de sua mãe. A partir dele é possível depreender que sua família gozava de privilégios típicos de uma família abastada. Sobre a casa em que viveram em Goiás, a filha diz:

A casa era uma alegre vivenda sôbre um outeiro, com uma porção de janelas verdes e um jardim na frente, comunicando com um terraço lateral. Jardim e terraços suspensos sôbre a cidade, desvendando um belo panorama.

O quintal - um vasto pomar... (GODOY, 1961, p. 8).

O jardim e o terraço revelam uma casa grande e confortável, provavelmente um palacete que contrastava muito com as choupanas e os casebres avistados pela família e registrados por Curado ao longo da viagem.

Sobre a autora do diário, é plausível dizer que, apesar de ter se resignado a deixar o Rio de Janeiro para viver em Goiás, não aceitou os costumes deste lugar. Embora a filha diga no prefácio que sua mãe "identificou-se de corpo e alma à terra do marido" (GODOY, 1961, p. 17), o fato de que "nunca soube sequer o gôsto de um pequi, e mesmo de uma pamonha..." (GODOY, 1961, p. 8) indica que havia algumas lacunas nesta identificação.

Todo o ambiente no qual viveu e no qual construiu suas referências deve ser levado em consideração para que seja possível compreender a visão que construiu em torno dos lugares que conheceu ao longo da viagem empreendida, especialmente a cidade de Araguari, lugar que ganhou espaço em dois pequenos capítulos do livro. Curado e sua família chegaram em Araguari na data de 29 de agosto de 1896 e permaneceram durante vinte dias, quando então continuaram a viagem rumo a Goiás.

Levando em consideração a historicidade de suas vivências, busquei fazer uma interpretação dos registros de suas memórias sobre a vida social em Araguari sem perder de vista as condições nas quais foram produzidas, especialmente no que diz respeito à perspectiva que marca aquele momento histórico.

O momento de sua vida e da viagem que a levou a passar por Araguari coincide com um período no qual estava colocada a necessidade de integração nacional, que se organizava com diversas frentes de colonização a partir de projetos como expansão de ferrovias e telégrafos que, para colonizar o Brasil, justificavam suas práticas enquanto missão civilizatória.

Ao pesquisar sobre a Comissão Rondon e a expansão de redes telegráficas como um projeto republicano que visava integrar e civilizar a nação, Laura Antunes Maciel traz elementos que corroboram as reflexões sobre este período. De acordo com a autora: 
a nação brasileira nos primeiros anos republicanos estava por um fio; ela não estava pronta, mas, no constante fazer-se que caracteriza a nação, ela estava em expansão para o Norte e o Oeste do País - via expansão de uma cultura técnica e positivista -, tentando transformar espaços "vazios" em territórios e "populações dispersas" em brasileiros, produzindo uma população homogênea capaz de se reconhecer como uma unidade e parte de uma "comunidade nacional". Essa ideia dá a dimensão da tensão cultural presente nesse fazer-se da Nação na sua busca por legitimidade, na afirmação de sua hegemonia e do poder republicano, enfrentando outras culturas e modos de vida, construindo identidades e homogeneidades onde antes existia uma diversidade - cultural, étnica e social. (MACIEL, 1998, p. 38-39).

Assim, não é à toa que Curado chega pelos caminhos traçados pela ferrovia. Ainda que a linha de tráfego de passageiros terminasse em São Pedro do Uberabinha - mais tarde, Uberlândia -, a família de Curado chegou a Araguari pelos trilhos da Estrada de Ferro, valendo-se de um trem de lastro - com seus vagões abertos - então utilizado por engenheiros.

A primeira impressão que Curado registrou da cidade evidencia a visão de um lugar no qual o projeto republicano de integrar e "civilizar" ainda não havia chegado, impressão que permanecerá ao longo de sua narrativa sobre Araguari:

Logo adiante, apareceu a primeira casa. Teto de palha, paredes de barro, uma choupana. Dormiam. Passamos. As choupanas foram se multiplicando até que em uma delas vimos à porta uma mulher, tendo na mão uma candeia de forma das candeias romanas. Seria uma pitonisa, procurando ler nos astros o destino dos homens? Ou algum espectro que, fugindo do túmulo, vagasse àquelas horas mortas? Nada disso. Era uma simples roceira, que acordava com o nosso tropel e vinha ver o que era! Corremos pressurosos para ela e indagamos da moradia de Alfredo. - "Lá embaixo, pra riba do hotel". Tão mal informados, procuramos achar o hotel. Casinha branca, sem taboleta, que, felizmente, estava aberta e, numa sala, alguns homens bebiam cerveja. (GODOY, 1961, p. 36-37).

O estranhamento ganha centralidade em sua narrativa. Se, para ela e o grupo ao qual pertencia, o Brasil era sinônimo de Rio de Janeiro e São Paulo, os lugares pelos quais passava, considerados como "interior", passam a ser vistos como uma região de gente inculta, de um povo que, para fazer parte da nação, necessitava ainda ser inventado. do Brasil

Valendo-me das palavras de Maciel, naquele momento, falar do interior, dos sertões

[...] era falar da região pouco além de Bauru, do "vazio" que a partir daí se estendia até o Paraná, de vastas porções de Mato Grosso, Goiás e Amazonas, estados que, no alvorecer da República, "não tinham visto ainda a entrada triunfal da locomotiva". (MACIEL, 1998, p. 96).

Trata-se de áreas de difícil acesso, por isso, tão estranhas a Curado e insistentemente registradas por ela como lugares abandonados. Essa concepção é construída e se fortalece ao longo de sua narrativa:

É uma cidade ainda nova; as casas são todas de telha á vent; não há um só sobrado. A Igreja data de tempos coloniais; os santos de colorido vulgar, muito vivo, parecem todos portugueses. O cemitério é um quadrado cercado por um muro branco. As sepulturas são rasas, tendo apenas uma cruz de madeira, onde se vê o nome do defunto. A grama cresce inculta, os animais lá entram a seu bel prazer; um cemitério abandonado, enfim. Junto do muro, do lado de fora, os tropeiros fazem fogo; não há respeito algum. No centro da cidade corre um riacho, que o divide em duas partes: de um lado tem nome de Goiás, e do outro, de Minas. A cadeia é velha e se assemelha a uma casa 
de banhos. O povo é bom e muito agradável. O comércio pequeno; há uma padaria, uma sapataria, duas farmácias e algumas casas de comércio. A cidade está a 750 metros acima do nível do mar. Venta sem cessar e a poeira é horrível! Um pó vermelho e pegajoso. (GODOY, 1961, p. 38).

Curado utiliza como mediadora a cidade do Rio de Janeiro a partir da qual traça comparações, identificando semelhanças e diferenças, construindo, assim, a partir dela, sua visão sobre Araguari. Por isso, certos valores e comportamentos por ela observados não condiziam com suas referências.

Partindo dessa perspectiva, reduz seus moradores a meros "roceiros ignorantes": "há ainda muitas superstições e costumes africanos por aqui. Pobre gente!" (GODOY, 1961, p. 38); "Vi um índio da tribo dos Cherentes [...] A falar a verdade, tive medo" (GODOY, 1961, p. 39). Além de demonstrar surpresa no fato de que as conversas de homens e mulheres eram sobre "galinhas, ovos, chuva, sol, a queda da ponte, a carestia de alimentos" (GODOY, 1961, p. 38).

Possivelmente, a desqualificação que faz da "pobre gente" que encontrou em Araguari esteja ligada à "tendência dos grupos dominantes" e intelectuais brasileiros naquele processo social vivido, de transição para o regime republicano, que negava as diferenças e idealizava um povo que deveria ser "fabricado".

Essa foi uma problemática abordada por Carlos José Ferreira dos Santos em sua obra "Nem tudo era italiano". A forma como estudou e desconstruiu o mito do imigrante europeu como modelo para a formação da nação brasileira contribui para as reflexões sobre como os trabalhadores nacionais, especialmente negros e índios, eram vistos. Ao estudar a cidade de São Paulo da virada do século XIX e do início do XX, Santos, preocupado em encontrar os trabalhadores nacionais, apresenta as diversas formas como estes eram desqualificados frente aos imigrantes europeus. Nos materiais pesquisados pelo autor, os imigrantes europeus aparecem como "os elementos indiscutíveis do nosso progresso" (SANTOS, 1998, p. 41), aqueles que "branqueariam" a cidade de São Paulo e quiçá o próprio país, contribuindo com o modelo de civilização cujo padrão idealizado era a Europa, assim como era nela que deveria ser espelhado o "desenvolvimento" desejado.

Ao operar distinção à medida que relata, Curado necessita identificar que encontrou ex-escravos e índios, o que indica um forte indício de que estes, assim como os nacionais pobres dos quais fala Santos, eram considerados fora dos padrões socioculturais desejados para a época.

Por isso, nas versões produzidas nos registros de sujeitos que viveram este processo histórico, os trabalhadores são tratados como uma "pobre gente" não-civilizada. Todavia, embora vistos dessa forma, o que interessa é que aquelas "pobres gentes" - negros libertos, índios ou camponeses - se intrometeram no dia a dia de Curado durante o período no qual permaneceu em Araguari, ganharam visibilidade social nos registros que produziu e que guardam evidências de práticas e modos de viver do final do século XIX.

Eram sujeitos que viviam em choupanas - assim definidas por Curado -, ou seja, casas construídas por eles mesmos com os materiais disponíveis, barro, madeira, palha; vivendo principalmente da produção de produtos agrícolas; utilizando a água do córrego que dividia a cidade para beber e, possivelmente, também para lavar suas roupas.

Essas presenças são evidências de práticas sociais que não ganharam espaço nas produções que optaram por narrar a gênese do município focalizando "bandeirantes e fazendeiros", mas que estavam ali na cidade real que nascia, imprimindo nela seus modos de viver.

Tendo em vista este horizonte de reflexão, e seguindo indícios deixados por Curado, importa destacar que, naquele final de século, ocorreu a inauguração da Estrada de Ferro Mogiana, que passou a ligar Araguari ao estado de São Paulo. Sobre esta inauguração, a viajante registrou as seguintes impressões: 
Inaugurou-se a Estrada de Ferro durante a nossa estada em Araguari. Imaginem que barulhada. Veio da roça não sei quanta gente para ver o "bicho que lança fogo e tem partes com o diabo"... Houve uma mesa de doces, brindes, muita cerveja. As senhoras em grande toalete, na Estação, esperando a máquina que vinha tôda enfeitada com bandeiras. Quando, porém, ela apitou, foi uma corrida por ali a fora. Mulheres tiveram ataques, homens velhos juraram que nunca se serviriam de semelhante cousa, que urra feito bicho e tem fogo no corpo. Os moleques corriam de pavor, derrubando os taboleiros de biscoitos. $E$ enquanto isso a máquina entrava triunfal na pequena estação de Araguari. Durante muitos dias só se falou na tal invenção do capeta. (GODOY, 1961, p. 39-40).

Embora, mais uma vez, Curado demonstre surpresa e ridicularize a reação daqueles que desconheciam a máquina a vapor, a ideia de "entrada triunfal" sugere que aquele acontecimento é visto por ela como um momento inaugural, não apenas da ferrovia, mas principalmente da própria cidade. É a visão da ferrovia desorganizando modos de viver que a autora considerava antiquados.

Em que pese o menosprezo que a autora delega àquela "pobre gente" ou aos que vieram da roça para a inauguração, a inegável historicidade que compõe o entrelaçar de trilhos e asfalto que permanecem em Araguari fez refletir acerca da "tal invenção do capeta" constituindo-se em elemento fundamental para a compreensão da natureza histórica desta cidade que, com a chegada da ferrovia, vai se organizar e se expandir ao redor das linhas do trem.

A partir dessa inauguração em 1896, Araguari passou a ser o ponto final da Companhia Mogiana de Estrada de Ferro. Esta tinha como função ligar a região do Triângulo Mineiro ao estado de São Paulo, sendo sua sede a cidade de Campinas. Anos depois tornou-se, também, o ponto inicial da Estrada de Ferro Goiás, instalada em 1909, cujo objetivo era ligar o estado de Goiás aos trilhos da Companhia Mogiana e com isso ao estado de São Paulo e, como consequência, ao litoral brasileiro. Seu ponto final era a cidade de Anápolis, mais tarde transferido para Goiânia, cuja estação foi inaugurada em $1950 .{ }^{73}$

As linhas do trem atuaram durante décadas em Araguari e estimularam uma profunda ligação entre esta cidade e o estado de Goiás. De acordo com a Revista dos Estados, por Araguari eram escoados produtos agrícolas, especialmente arroz, feijão, algodão, cana-deaçúcar, alho, trigo, mandioca e fumo, além de rebanhos de bovinos, equinos e suínos e produtos industrializados como charque, aguardente, farinha de mandioca, de trigo e de milho, manteiga, leite, banha, cortiça, guaraná, rapadura, calçados, doces, massas, biscoitos, café torrado e moído. ${ }^{74}$ Ou seja, uma produção que, vinda do campo, era transformada em outros produtos na cidade, ou ainda, apenas transportada para outras regiões, especialmente indo ou vindo do estado de Goiás, cujas cidades escoavam sua produção e adquiriam produtos por meio dessas empresas ferroviárias.

\footnotetext{
73 Importa dizer que ser o ponto final e inicial dessas empresas também significava colocar a cidade em um lugar de poder político e econômico na região. Lugar este que era constantemente disputado e que foi perdido com a transferência, em 1954, da diretoria da Estrada de Ferro Goiás para Goiânia. Em 1957, a Estrada de Ferro Goiás foi incorporada à Rede Ferroviária Federal S/A - RFFSA, permanecendo o funcionamento da estação de passageiros na cidade até 1973, quando, então, foi inaugurado um novo terminal ferroviário, na Avenida Coronel Belchior de Godoy, próximo à saída para Caldas Novas, e encerrando o transporte de passageiros na cidade. O que levou à desativação da Estação da Goiás. O prédio da estação voltou a ser utilizado apenas em 2005, quando passou a ser sede da Prefeitura Municipal. Também a Companhia Mogiana de Estrada de Ferro foi incorporada, em 1971, pela Ferrovia Paulista S/A - FEPASA e encerrou suas atividades em Araguari em 1973. No final da década de 1970, o prédio da estação desta companhia foi demolido para a abertura da Avenida Batalhão Mauá. Para compreensão desse processo foi importante a pesquisa nas Atas da Câmara Municipal e no Jornal Gazeta do Triângulo da década de 1950, assim como as seguintes leituras: Pereira (2006) e Peixoto; Vieira (2012).

74 Esses são os produtos que encontrei de forma recorrente ao longo da pesquisa e que são referenciados também na REVISTA DOS ESTADOS, Rio de Janeiro, ano XLIX, n. 407, ago. 1955, p. 3.
} 
Além disso, as trocas não podem ser resumidas apenas ao movimento comercial. A ferrovia trazia também pessoas que, por motivos diversos, começavam a utilizar o transporte ferroviário. Para atendê-las foram construídos bares, restaurantes, hotéis, pousadas etc.

Como parte do processo "civilizatório" aberto pelas ferrovias chegaram também padres holandeses da congregação dos Sagrados Corações de Jesus e Maria e freiras belgas da Congregação de Maria, com a missão de evangelizar e "educar" a população desta região. Não por acaso foram fundadas por eles escolas confessionais particulares - o Colégio Sagrado Coração de Jesus (1919), para meninas, e o Colégio Regina Pacis (1926), para meninos -, ambos voltados para o atendimento de filhos de famílias abastadas da cidade e região.

Assim, ao abrigar essas duas ferrovias, Araguari passava a ser um ponto estratégico para a circulação de mercadorias e pessoas que iam e vinham a partir dos trilhos da Mogiana e da Goiás.

Trata-se de um processo que foi vivido também em outros lugares, como parte do projeto de integração nacional e de alteração nos padrões de acumulação de capital. Ao pesquisar a Companhia Paulista de Estradas de Ferro, Célia Rocha Calvo refletiu sobre a força transformadora que a ferrovia impelia aos locais por onde passava. Associada aos interesses de seus proprietários e de fazendeiros que necessitavam de mão de obra e de escoar sua produção, a expansão ferroviária foi responsável pelo crescimento de pequenos povoados, bem como pela fundação de cidades. Espaços estes que passavam a ser planejados para atender os interesses desses grupos.

Segundo Calvo, essas práticas foram responsáveis também pela alteração das relações sociais que podem ser observadas:

[...] no movimento de remodelação do espaço público, na constituição de novos códigos para regular modos de viver e de comportar das pessoas, no fortalecimento dos poderes públicos locais, desencadeando novas práticas e instituições que procuravam estabelecer o controle da vida e do trabalho dos velhos e novos moradores. (CALVO, 1994, p. 27-28).

Em Araguari, esse processo não foi diferente. Ao observar o traçado da cidade, é possível perceber a forma como ela foi organizada ao redor dessas empresas ferroviárias e de outras empresas que ali passaram a se estabelecer a partir de suas relações com as ferrovias.

Com a chegada das ferrovias, a cidade, que no final do século XIX tinha apenas "uma padaria, uma sapataria, duas farmácias e algumas casas de comércio" (GODOY, 1961, p. 38), vai se expandindo no entorno do entroncamento entre a Companhia Mogiana de Estrada de Ferro e a Estrada de Ferro Goiás e próximo ao córrego Brejo Alegre. Indícios permanecem em sua arquitetura. Nessas áreas, ainda podem ser vistos antigos prédios que serviram como hotéis, casas comerciais, armazéns, fábricas - principalmente serrarias, charqueadas, curtumes, máquinas de beneficiar arroz e olarias.

Frente a essas transformações colocava-se também a expectativa das classes que se faziam dominantes sobre como a cidade deveria ser organizada. Para elas, fazia-se necessário racionalizar seu plano, ou mesmo criar um "plano" para a cidade, adaptando-a às exigências da circulação. ${ }^{75}$

Este plano foi solicitado pela Câmara Municipal e pelo Agente Executivo ao então engenheiro ferroviário Achiles Widulick, que fora responsável pela construção do trajeto da Companhia Mogiana de Estradas de Ferro entre Uberlândia e Araguari. O projeto apresentado por ele foi aprovado e sua proposta se materializou na Lei $\mathrm{n}^{\circ} 50$ de 1898, que determinava a demarcação, o alinhamento e o nivelamento de ruas e praças de Araguari.

\footnotetext{
${ }^{75}$ Sobre as necessidades que impulsionam a produção de planos para as cidades, ver: Roncayolo (1984, p. 440).
} 
Assim, junto com as ferrovias, vieram também as reformulações do traçado da cidade. Em outras memórias, essas transformações foram foco de preocupação, evidências dessas profundas transformações. Dentre elas, destacam-se algumas considerações feitas pelo padre Elói Kee, no livro que escreveu sobre a história do Colégio Regina Pacis.

$\mathrm{Na}$ introdução do livro, intitulado "Histórico do Colégio Regina Pacis", ${ }^{76}$ seu autor afirma que escreveu esta obra a partir da insistência de Abdala Mameri ${ }^{77}$ e com a intenção de deixar registrados "alguns episódios da história do Regina Pacis" (KEE, [197-?], p. 5), colégio fundado em 1926 por padres holandeses da Congregação dos Sagrados Corações de Jesus e Maria.

Importa dizer que esses padres chegaram na região no início do século $X X$ como missionários que, por meio da difusão do ensino formal, objetivavam também difundir, ou mesmo reafirmar, o catolicismo. Assim, seu livro fala das adversidades vividas por eles em "benefício da Pátria e da Igreja" (KEE, [197-?], p. 8).

Ao longo do livro, foram registradas memórias que dizem respeito a essas experiências. E direcionado a um público leitor que seria principalmente o religioso, que porventura buscasse conhecer melhor como foi a atuação dessa congregação em Araguari, e ex-alunos. Estes alunos eram provenientes de famílias que podiam arcar com os custos da educação formal, tratando-se, especialmente, de filhos de comerciantes e fazendeiros que naquela época estudavam no colégio em regime de internato.

Todavia, embora o foco tenha sido o colégio, Kee registrou pautas que estavam presentes nas "rodas de conversa" daqueles que compartilharam desses projetos "civilizatórios" ou de expansão das relações capitalistas pelo "sertão":

No começo deste século [XX], mormente após tornar-se terminal da Estrada de Ferro Mogiana, Araguari sentia-se colocada entre as cidades com grande futuro.

[...] Cochichavam que Araguari seria Nova Chicago; o progresso haveria de ser irresistível.

Bem acertadamente contrata-se urbanista famoso que projeta a planta perimetral, circundada de largas avenidas. Araguari estava preparada para receber o futuro. Até hoje merecem louvor os iniciadores desta medida previdente.

Contudo, embora as ruas novas se alargassem e as praças projetadas fossem respeitadas, Araguari provisoriamente continuava sendo cidadezinha do interior.

As ruas e praças planejadas ofereciam farto pasto aos equinos e bovinos e as datas espaçosas serviam otimamente de chiqueiros. As galinhas e demais galináceos vasculhavam livremente sem serem incomodadas, a não ser pelos vira-latas. (KEE, [197-?], p. 7).

Sua narrativa descortina o elemento da contradição no interior desse projeto: ao que tudo indica, havia uma distância entre aquilo que era projetado e aquilo que de fato era vivido.

A forma como o autor indica ver e viver a cidade fundamenta sua comparação com Chicago, cidade que Kee tinha em seu horizonte de expectativas, ou seja, uma cidade

\footnotetext{
${ }^{76}$ Embora não tenha sido publicado, encontra-se disponível para pesquisa no Arquivo Público Municipal de Araguari e Museu Histórico Dr. Calil Porto. Trata-se de uma fotocopia de 186 páginas datilografas e encadernadas, sem referência ao ano de sua produção, mas que, se levarmos em consideração que o falecimento do autor ocorreu no ano de 1975, é possível inferir que o livro foi escrito entre o final da década de 1960 e o início de 1970.

77 Conhecido como professor Abdala, foi funcionário do Banco do Brasil, redator-chefe do Jornal Gazeta do Triângulo, vereador na década de 1980 pelo PMDB, membro-fundador da Academia de Letras de Araguari. Fez parte da comissão organizadora da Casa da Cultura, foi co-responsável pela organização do Arquivo Público Municipal e escritor de livros sobre a cidade. Em sua homenagem, a Casa da Cultura recebeu seu nome. Existe também uma sala com seu nome no interior da Escola Estadual Raul Soares.
} 
industrializada que, no final do século XIX, já tinha uma população estimada em mais de um milhão de habitantes e que concentrava uma malha que agrupava dez linhas ferroviárias. ${ }^{78}$

Para além de Chicago, imaginando quais seriam as outras cidades de grande futuro, entre as quais Araguari "poderia" se colocar, poderíamos tomar como possíveis referências as cidades de São Paulo e Rio de Janeiro que neste mesmo período passavam por profundas transformações.

Muito já foi escrito sobre estas duas cidades, especialmente no que diz respeito ao final do século XIX e início do século XX, período marcado pelo início da República e pelo fim, na forma da lei, do trabalho escravo. ${ }^{79}$ Nessas cidades, foram engendradas, nesse momento, novas formas de viver, de pensar, novos projetos, a entrar em choque com interesses de grupos dominantes que tentavam manter seu poder advindo de um passado colonial. São cidades que começavam a se industrializar e atrair inúmeras pessoas que as buscavam, seja para estabelecer diversos tipos de negócios, seja procurando oportunidades de trabalho. Essa atração levou a um grande crescimento populacional: São Paulo, que de 31.385 habitantes em 1872, chegou a 1920 com 579.033 habitantes; 80 e a cidade do Rio de Janeiro, que, no mesmo período, passou de 274.972 para 1.157 .873 habitantes. ${ }^{81}$ Por isso, elas necessitavam ser abastecidas, além de servirem como escoadouro para a produção nacional.

O que difere Araguari de Chicago e de outras cidades do Brasil é o modo como a história é vivida, por isso, ainda que de formas diferentes, nela também se expressaram mudanças que fizeram das cidades um mercado de trabalho. Além disso, a comparação abre alguns caminhos para reflexão e instiga algumas indagações: o que a "cidade futurista" projetava sobre a cidade que de fato existia? O que naquele momento significava urbanizar?

As memórias registradas por Kee produzem sentidos e significados sobre as histórias vividas por ele, por isso trazem as contradições nesse processo de mudanças que ocorreram, não apenas no traçado da cidade, mas também nos modos de vivê-la. A cidade que estava sendo projetada ia na contramão dos modos de viver de trabalhadores que lembram muito aqueles encontrados por Curado em 1896, criando galinhas, bovinos e suínos para o próprio sustento e morando em casas construídas por eles mesmos com os materiais que encontravam disponíveis.

Todavia, a Araguari que Curado conheceu estava se transformando. Embora Kee também compartilhe da noção de "cidadezinha do interior", as memórias que produziu sobre seu traçado indicam intervenções que trazem à tona projetos que buscavam ordenar a "cidadezinha" que, com a chegada da ferrovia, começava a se modificar.

Essas tentativas de intervenção na cidade ganharam espaço também no livro "Pelos caminhos da História. Pessoas, coisas e fatos de Araguari", escrito por Abdala Mameri. $\mathrm{O}$ capítulo dedicado à figura do alinhador contribui para aprofundar a compreensão e as reflexões sobre as necessidades que permeavam este projeto de uma "cidade do futuro".

No capítulo intitulado "O alinhador" fica explícita sua intenção de mostrar os esforços que foram empreendidos para que Araguari pudesse possuir o traçado que ele qualifica como invejável. Todavia, a contraleitura desse capítulo abre outros caminhos de reflexão e impulsiona a ideia de que a transformação ocasionada pela ferrovia conduziu a disputas e à tentativa de imputar valor de troca à terra urbana, subtraindo-lhe os sentidos de uso:

Desde os primeiros habitantes que para cá vieram, nas primeiras décadas do século 19, cada um procurou assenhorear-se de terrenos, quanto maiores melhores, para neles instalar residências e casas comerciais. Em volta eram

\footnotetext{
78 Sobre a cidade de Chicago (EUA), foram consultados os seguintes sítios eletrônicos: <http://www.easyexpat.com/pt/guides/usa/chicago/visao-geral/historia.htm\#.Uvdg-fldXy0>; <http://operamundi.uol.com.br/conteudo/historia/24749/hoje+na+historia+1871+\%96+centenas+morrem+no+gr ande+incendio+de+chicago.shtml>. Todos acessados em: 8 fev. 2014.

79 Dentre estes escritos, destaco: Cruz (1991); Santos (1998); Cruz (2000); Cunha (2001); Silva (2006).

80 IBGE - Séries Históricas e Estatísticas. Disponível em:

<http://seriesestatisticas.ibge.gov.br/series.aspx?vcodigo=CD79>. Acesso em: 9 set. 2013.

81 Ibidem.
} 
propriedades rurais, a perder-se de vista pela sua imensidão e que foram depois sendo divididas, como conseqüência de heranças ou vendas parciais. Com o aumento da população, tornou-se necessária construção de mais prédios, o que obrigou o presidente da Câmara Municipal e agente executivo a tomar providências, no sentido de defender o traçado da cidade.

O assunto era inicialmente discutido na Câmara, onde o alinhador era indicado e seu nome deveria ser aprovado. Em seguida, dava-se a nomeação, ocasionando-lhe poderes para o desempenho do delicado cargo. (MAMERI, 1988, p. 36).

Apesar de Mameri não falar sobre os possíveis motivos para o aumento da população de Araguari, dados demográficos indicam que o município que possuía 10.633 habitantes no início do século XX chega à década de 1930 a 35.000 habitantes, mais que triplicando sua população em curto espaço de tempo. Assim, embora não tenha sido possível encontrar pesquisas que indicassem os índices de natalidade, é possível inferir que esse aumento de mais de $300 \%$ da população tenha ocorrido devido à chegada de novos moradores à cidade, que para ela vieram na esperança de encontrar oportunidades de emprego oferecidos pelas empresas ferroviárias ou por outras empresas construídas em função das ferroavias. ${ }^{82}$

Tendo em vista esse horizonte, torna-se possível problematizar a interpretação apresentada por Mameri, de que a contratação de um alinhador foi uma prática que visava organizar e embelezar Araguari. Frente a essa realidade que se apresentava, alinhar a cidade significava não apenas ordenar sua forma, mas, principalmente, ordenar os usos de seus espaços por essa população de trabalhadores que passou a aumentar consideravelmente e, consequentemente, a criar novos espaços saturados por seus modos de viver.

A leitura e a reflexão sobre esses e outros registros dos quais tratarei a seguir levaram a compreender que essas intervenções não se resumiram à tentativa de organizar fisicamente a cidade para atender os interesses ligados à circulação de mercadorias e pessoas; eles produziram também espaços diferenciados de práticas e modos de viver permitidos e/ou reprovados.

Nesse sentido, contribuem com esta reflexão algumas proposições apresentadas por Fábio Macedo Tristão Barbosa que, em sua dissertação de mestrado, trabalhou com o pressuposto de que "a cidade e o urbano se organizam e são comandados em função de e a partir da ferrovia" (BARBOSA, 2008, p. 14). De acordo com o autor:

Embelezar também significava retirar os inconvenientes e os indesejáveis de determinados espaços da cidade, principalmente da região central; daí, temas como higiene e saúde figurarem entre as preocupações dos administradores públicos, legitimando ideologicamente suas ações na tentativa de erradicar a presença dessa população menos afortunada no centro da cidade, que passa a habitar sua periferia. (BARBOSA, 2008, p. 9798).

A pesquisa empreendida por Barbosa reafirma a posição de que a ferrovia e o consequente aumento da população conduziram à necessidade de uma redefinição territorial que vai sendo continuamente refeita ao longo do tempo, por meio de leis para impor um "ordenamento" que visa determinar o lugar que caberia aos trabalhadores nesta cidade.

\footnotetext{
${ }^{82}$ A escassa exatidão dos dados demográficos para o final do século XIX e início do XX para Araguari não invalida a reflexão proposta, uma vez que, ainda que precários, oportunizam inferir sobre as transformações que estavam ocorrendo no percentual populacional deste período na cidade. Esses números foram encontrados nas seguintes fontes: dados demográficos publicados no Jornal Gazeta do Triângulo em 18 de outubro de 1960; artigo publicado no Jornal Diário de Araguari sobre a "evolução" urbana da cidade, no qual é feita referência à chegada de 352 trabalhadores no ano de 1911, contratados pela Estrada de Ferro Goiás. Ver: VOCÊ sabia? Araguary - Evolução Urbana - Parte I. Jornal Diário de Araguari, 29 e 30 mar. 2009.
} 
Urbanizar significava, assim, interferir com o objetivo de modificar práticas sociais vividas, propondo um novo estilo de vida. ${ }^{83}$ Muitas dessas modificações, intervenções e legislação urbana datam do final do século XIX e do início do século XX. ${ }^{84}$ Porém, a reflexão sobre elas se aguçou quando encontrei a Lei no 271, de 3 de novembro de 1923, expedida anos antes da inauguração da Estação de Passageiros da Estrada de Ferro Goiás, cuja instalação dos trilhos teve início em 1909, sendo a estação de passageiros inaugurada apenas em 1929.

Essa Lei traz evidências da produção de espaços de privilégio a partir da diferenciação social. Isso porque, ao propor normas para as intervenções nos espaços físicos da cidade, tentou delimitar o direito de acesso a esses espaços a partir do lugar social ocupado por seus moradores.

A Lei no 271, de 3 de novembro de 1923, dividia a cidade em três zonas: a zona urbana, cujos limites eram a Avenida São Paulo, a linha de ferro da Estrada de Ferro Mogiana, as avenidas Bahia, Minas Gerais e Moto Grosso; a zona suburbana, que compreendia tudo o que estivesse fora desses limites; e a zona especial, "encravada" na zona urbana da seguinte forma:

partindo da praça João Pinheiro [atual Praça Manoel Bonito], segue pela rua Ruy Barbosa até a rua da Estação [atual Marciano Santos]; por esta até a rua Rio Branco; por esta, até a praça da República; por esta, incluída toda a praça, e da mesma forma a de nome José Rodrigues Alves, até a rua João Peixoto; por esta e pela rua Tiradentes até a praça João Pinheiro; a direita, por esta praça, até o ponto inicial. (PREFEITURA MUNICIPAL DE ARAGUARY, 1923, p. 15).

Para fins de regulação, de acordo com o Artigo 90 da Lei, as mesmas normas deviam ser aplicadas às seguintes ruas:
a) - Affonso Penna e Estação, desde a rua Tiradentes até o extremo das mesmas;
b) - Municipal e Boa Vista;
c) - Liberdade e Goyaz, do seu inicio até a rua Boa Vista;
d) - Matriz; do seu inicio até o largo do Rosário;
e) - Rodolfo Paixão, entre Rio Branco e Tiradentes;
f) - Maricota Santos;
g) - Aureliano de Oliveira. (PREFEITURA MUNICIPAL DE ARAGUARY, 1923, p. 15).

Essas são vias e espaços públicos que, além de compor o centro comercial da cidade, congregavam as residências de famílias abastadas que ali haviam construído seus palacetes, aberto suas clínicas e consultórios, seus comércios e suas empresas. Eram latifundiários, industriais, advogados, médicos, proprietários de jornais, enfim, pessoas que tinham seus nomes projetados publicamente e que desejavam manter essa área como seus espaços de vivência.

Desta forma, essa tentativa de delimitação de uma zona especial a partir de uma proposta que visava normatizar a cidade evidencia disputas por seus espaços, a partir do estabelecimento de regras para seu uso e sua ocupação.

Essa divisão em setores estabelecia diversos critérios para sua ocupação, dentre os quais a necessidade de licença para construção, reconstrução e demolição que apenas seria concedida mediante aprovação dos planos e projetos da obra pelo Agente Executivo.

\footnotetext{
83 Para essas reflexões, foi importante ler: Roncayolo (1984, p. 396-487).

${ }^{84}$ Dentre elas, destaco a Lei no 50 , de 4 de fevereiro de 1898, que determinava o alinhamento e a demarcação de vias públicas (anunciada apenas dois anos depois da inauguração da Estação de Passageiros da Estrada de Ferro Mogiana) e a Lei no 96, de 1901, que alterava a referência de algumas ruas da cidade, substituindo os números que Ihes foram atribuídos por nomes.
} 
Os projetos de edificação deveriam informar, entre outras coisas: a divisão do prédio, o tamanho dos cômodos, espessura da parede e a qual fim se destinava. Previa também multa e possibilidade de demolição para obras que fossem modificadas clandestinamente. Todas as obras deveriam ter um construtor "diplomado" responsável e matriculado na seção de obras da Prefeitura Municipal. Ao assumir a obra, o construtor se tornava seu responsável, sendo obrigado a informar irregularidades, atrasos e outras ocorrências.

Inegavelmente nem todos poderiam atender às exigências estabelecidas e isso é tão claro que ficou previsto na própria Lei, que também delimitou o espaço no qual poderiam ser tolerados outros modos de viver: a zona suburbana, ou seja, a área que naquele momento era periferia da cidade. Esse limite era reforçado quando a lei proibia também, na zona urbana:
a) - construcção de meia água, que não seja para despejo;
b) - construcção de chalet com oitão voltado para a rua;
c) - cobertura de madeira, capim ou outro material inflammavel; da mesma forma zinco liso ou enrugado, salvo nas fabricas e officinas;
d) - emprego de alvenaria de tijolo nas fundações;
e) - uso de barro amassado na constituição das alvenarias das paredes das casas;
f) - emprego de columnas de madeira para sustentação de cargas permanentes;
g) - construcção de paredes externas exclusivamente de madeira, salvo quando destinadas a officinas, construídas em alinhamento afastado da rua; h) - construção de adobos ou esteios de madeira nas frentes das casas da zona especial;
i) - construcções capazes de polluir ou prejudicar para o uso ordinário a água do poço ou fonte alheia a ellas preexistentes;
j) - construcção de esgoto que despeje água servida na sargeta da rua. (PREFEITURA MUNICIPAL DE ARAGUARY, 1923, p. 9).

Estabelecia ainda, para as edificações, a altura mínima de quatro metros, bem como deveriam ser a pavimentação, a calçada, as portas e janelas, os banheiros, a iluminação, os forros, o escoamento de água e os telhados. Mas fazia exceções para a zona suburbana, na qual as construções poderiam ter pé direito inferior a quatro metros, além de não precisar ter forro e assoalho.

De acordo com esta Lei, deveriam ser oferecidos "gratuitamente os planos das casas suburbanas, de valor inferior a 1:500\$000, quando, a juízo do Agente Executivo, os respectivos proprietários não possam pagar as despesas do projecto" (PREFEITURA MUNICIPAL DE ARAGUARY, 1923, p. 4).

O Artigo 55 proibia na zona especial "estabulos, estribarias, pocilgas e quaesquer outras construcções cujo destino seja prejudicial à saúde pública, salvo si obdecerem aos requisitos exigidos pelo regulamento da policia sanitária" (PREFEITURA MUNICIPAL DE ARAGUARY, 1923, p. 9-10).

As proibições e "concessões" arroladas na Lei evidenciam modos de viver que lembram muito a "pobre gente" da qual falava Curado. Casas de madeira, meia água, barro amassado, telhado de capim constituíam modos de morar das classes trabalhadoras que, além de construir suas casas sem seguir projetos, muito menos contratar construtor "diplomado", também aproveitavam seus quintais para a criação de animais para consumo próprio, ou ainda, para abrigar outros que lhes servissem como meio de transporte e trabalho.

Todas essas exigências faziam com que a construção de casas nas zonas urbana e especial ficassem restritas aos poucos que detinham condições financeiras suficientes para cumprir tais imposições. Assim, a justificativa de preservar a saúde pública, garantindo condições sanitárias adequadas, restritas às zonas urbana e especial, indica que essa era uma forma de retirar grupos considerados indesejáveis ou inidica que estes poderiam receber tratamento sanitário diferenciado, uma vez que, desde que longe do espaço reservado aos grupos dominantes, Ihes era permitido manter alguns de seus modos de viver. 
Por meio de códigos como esse, tentava-se impor limites a um espaço, então constituído por práticas plurais. Afinal, na zona especial também era constante a presença de engraxates, entregadores, charreteiros, vendedores, comerciantes de rua, enfim, trabalhadores que faziam dessa zona também um espaço de trabalho. Portanto, materializase nesse código a intenção de empurrar de forma seletiva alguns grupos para a periferia da cidade, fazendo da área denominada como zona especial um espaço de privilégio.

Essas são práticas que não foram inventadas em Araguari. Elas são concernentes a um processo que não se restringe a esta cidade, mas que ocorreu em todo o Brasil ainda que com nuances diferentes. Por isso, é possível inferir que tais práticas se inspiravam em cidades como Rio de Janeiro e São Paulo que, na virada do século XIX e no início do século XX, empreenderam esforços para "modernizar" os espaços considerados como urbanos. ${ }^{85}$

Essa "modernidade" era imposta a partir da remodelação da cidade, valendo-se da abertura de novas e largas avenidas; da demolição de cortiços; de campanhas sanitárias e de branqueamento da população, que se davam através de ações repressoras, como o botaabaixo empreendido no Morro do Castelo no Rio de Janeiro que objetivava expulsar da cidade uma população malquista.

Mais do que intervenções sobre o espaço, essas práticas significaram, sobretudo, tentativas de moralização e disciplinarização da classe trabalhadora, além da tentativa de expulsar da cidade os elementos considerados indesejáveis.

Nessa perspectiva, se faz salutar recolocar algumas proposições formuladas por Raquel Rolnik, no livro "A cidade e a lei". Preocupada em problematizar a legislação urbana da cidade de São Paulo, sua pesquisa estimula pensar essas leis como tentativa de criação de uma cidade desejável, na qual diferenças culturais e de classe seriam "organizadas" de forma hierárquica com o objetivo de garantir o poder e o espaço de grupos dominantes. Segundo Rolnik:

Mais do que definir formas de apropriação do espaço permitidas ou proibidas, mais do que efetivamente regular a produção da cidade, a legislação urbana age como marco delimitador de fronteiras de poder. A lei organiza, classifica e coleciona territórios urbanos, conferindo significados e gerando noções de civilidade e cidadania diretamente correspondentes ao modo de vida e à micropolítica familiar dos grupos que estiveram mais envolvidos em sua formulação. Funciona, portanto, como referente cultural fortíssimo na cidade, mesmo quando não é capaz de determinar sua forma final. (ROLNIK, 2006, p. 13).

Tendo em vista esta perspectiva, ao me aproximar das reflexões sobre o processo de construção de uma legalidade urbana que tomou como referência um padrão único, foi possível compreender que essa diferenciação de tratamento entre as classes sociais, traçadas na legislação urbanística de Araguari, descortina o fato de que todas essas regulamentações sobre o uso da terra urbana, embora sejam apresentadas como um meio de organizar, higienizar e "embelezar" a cidade, são, na realidade, evidências de práticas que reproduzem geograficamente diferenças sociais.

Nessa direção, importa ainda destacar que as tentativas de interferir nos modos de viver das classes trabalhadoras são refeitas ao longo do tempo. Valendo-se de códigos, normas e concessões, elas tiveram, nas reformas empreendidas durante décadas sobre 0 leito do Córrego Brejo Alegre, uma de suas maiores expressões. Tais reformas foram realizadas em várias fases. Assim, embora tendo seu início na década de 1940, as intervenções chegaram até o início dos anos 2000 com a canalização do córrego com tubulação fechada, o que indica que este é um espaço vivido que está em constante disputa e por isso também passa por frequentes intervenções.

\footnotetext{
${ }^{85}$ Sobre esse processo, foram fundamentais as leituras das seguintes obras: Rolnik (1997); Santos (1998); Silva (2006).
} 
A fotografia a seguir evidencia a tentativa de higienizar um espaço que, para além de ter sido inicialmente um limite geográfico que dividia a cidade em duas partes, demarcava também uma fronteira social.

Fotografia 01 - Abertura do leito do Córrego Brejo Alegre (antiga Avenida Sanitária). Década de 1950.

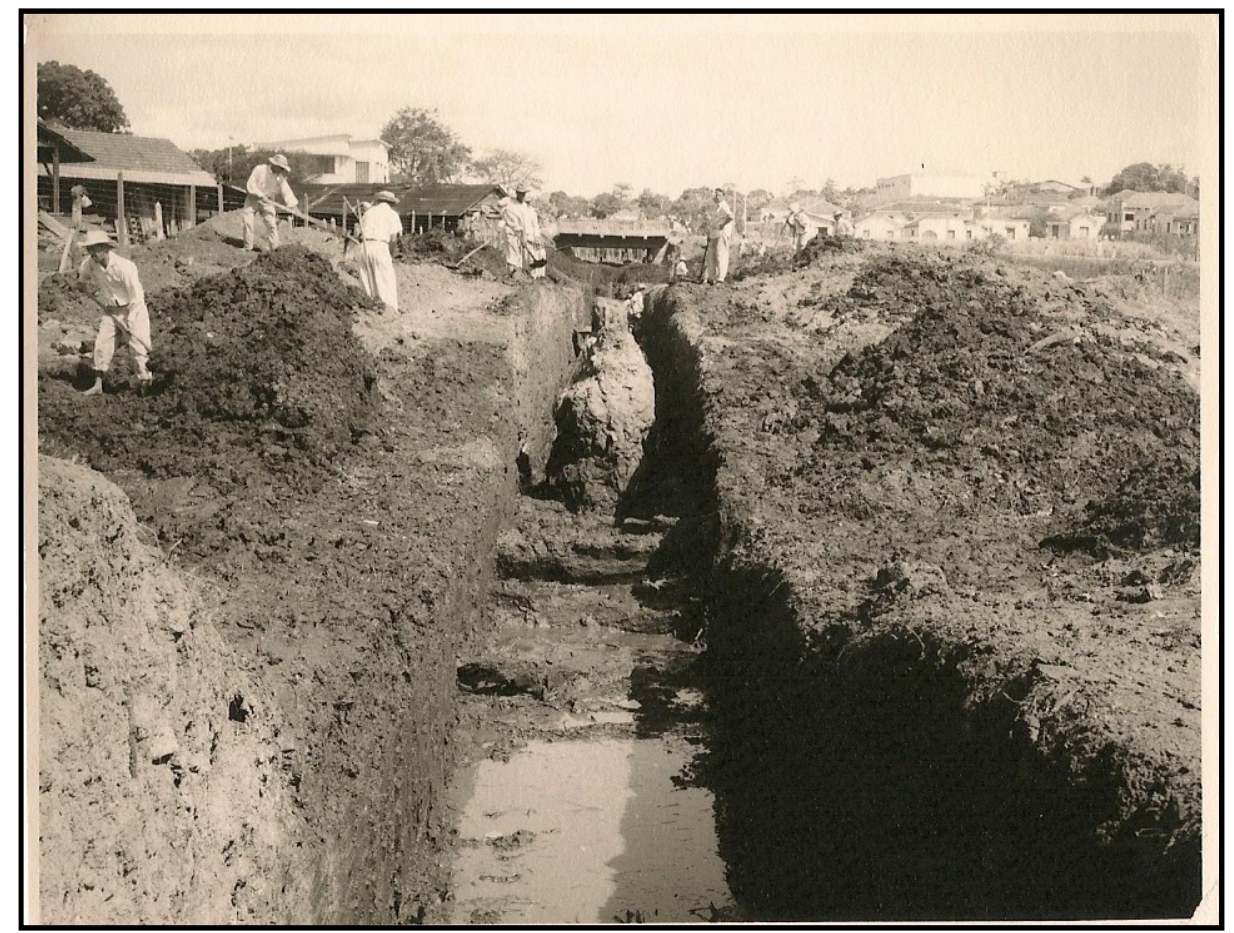

Fonte: Acervo do Arquivo e Museu Histórico Municipal “Dr. Calil Porto” (n. 5.23). Fotógrafo: Geraldo Vieira.

Importa dizer que, embora não tenha sido possível saber quais fotografias foram produzidas por iniciativa própria e quais foram financiadas, por meio do jornal Gazeta do Triângulo tomei conhecimento de que, no caso específico das obras de revestimento e retificação do Córrego Brejo Alegre, o fotógrafo Geraldo Vieira ${ }^{86}$ foi contratado pelo então prefeito municipal em exercício, Moises de Carvalho Alves (1957-1958).

Com a intenção de se enaltecer por ter sido o divulgador da ideia que depois foi acatada pela Prefeitura Municipal, foi explicitado nas páginas deste jornal que o objetivo de fotografar seria para produzir álbuns fotográficos de locais da cidade que estavam sendo modificados para que, no futuro, pudesse ser comparada "a cidade moderna com a cidade antiga" ${ }^{87}$ Assim, seria possível ter "elementos fotográficos para a reconstituição da evolução da cidade, sob o aspecto urbanístico". ${ }^{8}$

Todavia, a questão aqui ultrapassa uma simples obra de "melhoria", como propunha no final da década de 1950 a Gazeta do Triângulo. Isso porque este espaço, no qual foram impostas inúmeras alterações, divide a cidade ao meio: de um lado, considerado como o lugar de fundação da cidade, temos a Igreja Matriz do Senhor Bom Jesus da Cana Verde, espaço que foi ocupado principalmente por fazendeiros e comerciantes; e, oposto a ele, do outro lado do córrego, a Igreja de Nossa Senhora do Rosário, que demarca, no social, um dos espaços

\footnotetext{
${ }^{86}$ Fotógrafo que trabalhou em Araguari entre os anos de 1935 e 1978. Seu acervo foi doado ao Arquivo Público Municipal e Museu "Dr. Calil Porto" e sua coleção de negativos foi tombada em 2006 como patrimônio histórico-cultural de Araguari.

87 NOSSA sugestão foi atendida. Jornal Gazeta do Triângulo, n. 1.485, Araguari, 23 jun. 1957.

88 Ibidem.
} 
vividos por trabalhadores, especialmente dos negros que moravam nas proximidades desta Igreja.

Portanto, "a evolução da cidade, sob o aspecto urbanístico",89 ou seja, as reformas que estavam sendo colocadas em marcha, faz parte das contínuas intervenções que vão sendo impostas à cidade como forma de submeter a realidade vivida "às exigências do mundo supostamente lógico, sem contradições nem conflitos, da mercadoria" (LEFEBVRE, 1999, p. 9). Por isso, concordando com as reflexões de Henri Lefebvre, a redução do urbano ao urbanismo deve ser entendida

como parte fundamental das tentativas de estender ao conjunto das atividades sociais os pressupostos, intencionalidades, representações que governam a divisão manufatureira do trabalho, com suas ordens e coações. (LEFEBVRE, 1999, p. 9).

Se a cidade não é uma realidade acabada, mas uma prática social em constante transformação, ao olhar para esta fotografia, mais do que comparar "a cidade moderna com a antiga", importa refletir sobre o que as obras, realizadas nesta área do córrego Brejo Alegre, buscavam de fato sanitarizar. Afinal, para além do "embelezamento", qual o efeito para aqueles que moravam nesta área da cidade?

Nessa direção, fizeram-se importantes as entrevistas que produzi com moradores da cidade sobre suas experiências de viver em Araguari. Dentre essas narrativas, a entrevista realizada com a senhora Cleusa Vieira ganha destaque.

Embora tenha vivido muitos anos no bairro Santa Helena, dona Cleusa, ao falar sobre sua vida em Araguari, inicia sua narrativa dizendo que nasceu na rua Dr. Alberto, em uma "casinha" "na beira do córrego", região considerada por ela como centro da cidade. Sobre os motivos que levaram sua família a deixar este lugar por volta do ano de 1973 para viver no bairro Santa Helena, dona Cleusa narra:

A gente não tinha condições, o aluguel foi apertando pro lado de cá... Aí começou a fazer a canalização de água, porque antes era, não sei se você já ouviu falar que era cisterna, a gente tirava água da cisterna. Aí a gente, começou a ficar difícil, porque aí a gente, a energia a gente até tinha, mas a gente não usava muito. Devido à situação, a gente acendia era vela, era lamparina na época, não sei se você já ouviu falar da lamparina. E começou canaliza, colocar água, né? $\mathrm{Na}$, na, nas ruas. Foi aí que passou a ter as torneira. Aí foi apertando pra gente pagar água, né? Pagar energia. Aí o que que aconteceu, a gente foi pra Santa Helena, mudar pra casa que não tinha água. A gente não tinha que pagar água, era na cisterna que a gente tirava. É uma situação muito difícil, situação muito difícil mesmo.

[...] Daí puxava água da cisterna. A gente mudava várias vezes, porque a gente não tinha condições de pagar o aluguel. A gente morava um mês numa casa, não pagava o aluguel, a gente mudava pra outra casa e... E era uma vida difícil demais, muito difícil. ${ }^{90}$

Ao narrar as experiências de sua família, a senhora Cleusa reelabora em suas memórias vivências que também faziam parte do horizonte de possibilidades de outros trabalhadores na cidade. A energia elétrica e a água encanada eram "benefícios" que pesavam na economia doméstica, além de valorizar a área que atendia, produzindo 0 aumento do aluguel.

Portanto, o que estava colocado nas reformas empreendidas neste espaço, era a valorização daquelas áreas cortadas pelo córrego e a transformação de seu valor de uso em valor de troca. Assim, tais remodelações ligam-se diretamente ao interesse de estimular,

\footnotetext{
89 NOSSA sugestão foi atendida. Jornal Gazeta do Triângulo, n. 1.485, Araguari, 23 jun. 1957.

${ }^{90}$ Entrevista realizada com a senhora Cleusa Vieira, 54 anos, no dia 28 de janeiro de 2013, em Araguari.
} 
neste espaço, outras formas de ocupação por meio da valorização comercial que a solidificação de terrenos ribeirinhos impulsionaria.

Nesse sentido, sua narrativa se transforma em uma evidência de que, enquanto para alguns a "modernidade" propagandeada pela Gazeta do Triângulo podia significar mais conforto, melhores condições de moradia, acesso a bens e serviços que lhes garantiriam não apenas bem-estar, mas, sobretudo, status social, para outros foi experimentada como aprofundamento da desigualdade social, uma nova tentativa de transferir os trabalhadores para as vilas, juntamente com o esforço para controlar o comportamento, os modos de trabalhar e de viver.

Essas tentativas de intervenção e regulação reiteram a concentração de poder nas mãos de alguns grupos que vão se firmando como modelos de como viver a cidade, mas que, no entanto, não foram capazes de eliminar os modos de viver dos trabalhadores. Afinal, se a cidade idealizada se destinava àqueles que se submetessem às normas estabelecidas, a maneira como essas normatizações são recolocadas ao longo do tempo indica que não havia um projeto único de como viver a cidade. Por isso, as propostas de intervenção tiveram que ser continuamente refeitas, objetivando a manutenção da hegemonia do grupo composto por comerciantes, industriais e latifundiários que nesse processo competem para se manter como dominantes.

Nessa direção, a dissertação de mestrado de Sérgio Paulo Morais, ao tratar da relação entre trabalho e cidade, contribui com esta reflexão ao inferir sobre a necessidade de vermos as práticas dos trabalhadores e as transformações impostas a seus modos de viver a partir de intervenções rotuladas de modernização, não como arcaicas ou anacrônicas, mas como disputas que se fazem no social pelo direito à cidade e aos valores que vão sendo transformados. Segundo Morais:

O processo de constituição e luta pelo espaço urbano é efetivamente um processo forjado no cotidiano da vida e trabalho de vários sujeitos. Por ser fruto de ações múltiplas e dispersas (e muitas vezes opostas), não é facilmente controlado por uma vertente ou um grupo mesmo que esteja este diretamente ligado ao poder público. (MORAIS, 2002, p. 71).

Quando cheguei a Araguari, no final dos anos de 1980, algumas práticas típicas da classe trabalhadora de áreas rurais ainda permaneciam. Recordo-me especialmente do canto de inúmeros galos que marcavam o amanhecer na cidade, principalmente no horário de verão quando o dia ainda estava escuro e meu irmão, alguns vizinhos e eu já nos encaminhávamos para a escola. Nessa época, a figura do leiteiro também fazia parte desse amanhecer, levando seu produto diretamente da roça para os moradores da cidade.

A permanência de práticas que foram, durante décadas, alvo de interferências indica que os projetos de cidade estão em disputa e mesmo aqueles que se colocam como hegemônicos não podem ser vistos como onipotentes.

\section{Bibliografia}

BARBOSA, Fábio Macedo Tristão. Ferrovia e organização do espaço urbano em Araguari (1896-1978). 2008. 179 f. Dissertação (Mestrado em Geografia) - Programa de PósGraduação em Geografia, Universidade Federal Fluminense, Rio de Janeiro, 2008.

CALVO, Célia Rocha. Trabalho e ferrovia: a experiência de ser ferroviário da Companhia Paulista. 1890-1925. 1994. 117 f. Dissertação (Mestrado em História) - Programa de PósGraduação em História, Pontifícia Universidade Católica de São Paulo, São Paulo, 1994.

CRUZ, Heloisa de Faria. Trabalhadores em serviços: dominação e resistência. (São Paulo - 1900/1920). São Paulo: Editora Marco Zero: CNPq, 1991. 
São Paulo em papel e tinta: periodismo e vida urbana - 1890-1915. São Paulo: Educ; FAPESP; Arquivo do Estado de São Paulo; Imprensa Oficial, 2000.

CUNHA, Maria Clementina Pereira. Ecos da folia. Uma história do carnaval entre 1880 e 1920. São Paulo: Companhia das Letras, 2001.

FENELON, Déa Ribeiro (Org.) Cidades. São Paulo: Olho D’Água; Programa de Estudos PósGraduados em História, PUC-SP, 1999.

GODOY, Maria Paula Fleury. Do Rio de Janeiro a Goiás - 1896. (A viagem era assim). S. I.: s. n., 1961, p. 8. (Esta publicação encontra-se disponível no Arquivo Público Municipal de Araguari).

GRUPO MEMÓRIA POPULAR. Memória popular: teoria, política, método. In: FENELON, Déa Ribeiro et al. (Org.). Muitas memórias, outras histórias. São Paulo: Olho d'Água, 2004.

KEE, Padre Elói. Histórico do Colégio Regina Pacis. [Araguari]: [s.n.], [197-?] (Livro fotocopiado. Acervo do Arquivo Público Municipal).

LEFEBVRE, Henri. A revolução urbana. Belo Horizonte: UFMG, 1999.

MACIEL, Laura Antunes. A nação por um fio. Caminhos, práticas e imagens da "Comissão Rondon". São Paulo: EDUC, 1998.

MAMERI, Abdala. Pelos caminhos da História. Pessoas, coisas e fatos de Araguari. Araguari: Artgraf, 1988.

MORAIS, Sérgio Paulo. Trabalho e cidade: trajetórias e vivências de carroceiros na cidade de Uberlândia. 1970-2000. 2002. 168 f. Dissertação (Mestrado em História) - Programa de Pós-Graduação em História, Universidade Federal de Uberlândia, Uberlândia, 2002.

PEIXOTO, Juscélia Abadia; VIEIRA, Aparecida da Glória Campos. A ferrovia em Araguari. Goiânia: Kelps, 2012.

PEREIRA, Viviane da Silva. Memórias a todo vapor: a transferência da sede da Estrada de Ferro Goiás (1954) na imprensa araguarina (1947-1954). 2006. 80 f. Monografia (Graduação História) - Universidade Federal de Uberlândia, Uberlândia, 2006.

PREFEITURA MUNICIPAL DE ARAGUARY. Lei $\mathrm{n}^{\circ}$ 271, de 3 de novembro de 1923. Regulamento das Construções, reconstruções e demolições de obras na cidade de Araguary, Araguari, 1923.

PREFEITURA MUNICIPAL DE ARAGUARI. Araguari: cem anos de dados e fatos. Araguari: Edição Prefeitura Municipal de Araguari, 1988.

REVISTA DOS ESTADOS, Rio de Janeiro, ano XLIX, n. 407, ago. 1955.

RONCAYOLO, Marcel. Cidade. In: ENCICLOPÉDIA Einaudi. Lisboa: Imprensa Nacional Casa da Moeda, 1984.

SANTOS, José Ferreira dos Santos. Nem tudo era italiano. São Paulo e Pobreza (1890195). São Paulo: Anablume; FAPESP, 1998. 
SILVA, Lucia Helena Pereira da. Luzes e sombras na cidade: no rastro do Castelo e da Praça Onze 1920/1945. Rio de Janeiro: Secretaria Municipal da Cultura, Departamento Geral de Documentação e Informação Cultural, Divisão de Editoração, 2006.

Recebido em outubro de 2016. Aprovado em novembro de 2017. 